\title{
Microbes reveal extent of biodiversity
}

Craig Venter is still sailing his Sorcerer II sloop around the world, but now he has got 6.3 billion base pairs of microbial DNA to show for it. The pioneer of large-scale genome sequencing has published the first data set from his global quest to sequence microbes from all the oceans.

In a series of papers published this week in PLoS Biology, an international team of researchers presents the first results from Venter's Global Ocean Sampling expedition (http://collections.plos. org/plosbiology/gos-2007. php). It follows an earlier, smaller study that uncovered rich microbial diversity in the

"You can overinterpret DNA sequence data, but if you're careful, you just use them as a clue."

to increase. The question, said Venter in a telephone interview from Sorcerer II as it bobbed its way through the Sea of Cortez, is how long will that increase continue? And how does one extract meaning from a pile of 6.3 billion As, Ts, Cs and Gs?

The Global Ocean Sampling results reported this week include sequences gathered from 41 locations in 2003 and 2004, from the northwest Atlantic to the eastern tropical Pacific. "The next phase is to try with a much larger data set from the entire circumnavigation," said Venter. "We want to find out if it starts to show any degree of saturation, or is the number of independent proSargasso Sea (J. C. Venter et al. Science 304, tein and gene families so vast that we are still $66-74 ; 2004)$. The analyses of the first set of 7.7 at the earliest stage."

million genetic sequences from the expedition reveal that the upper limit on ocean diversity has yet to be set.

The papers point to 1,700 new protein families. Surprisingly, the rate of discovery stayed more or less the same as the number of new sequences grew, suggesting that the number of new protein families will continue
The team has faced some challenges. It has to predict protein sequences on the basis of the DNA sequences it retrieves from its samples. This can be tricky, because not all DNA codes for protein, and some bits of DNA can be read in different ways to produce different protein sequences. It will be important to go back and confirm that the predicted proteins are actu-

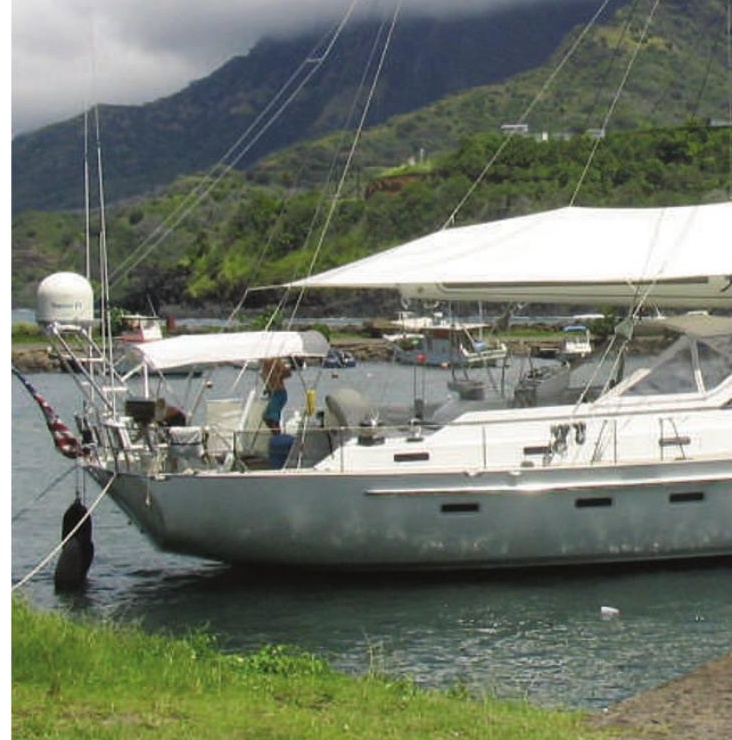

ally made, says Monica Orellana, a systems biologist at the Institute for Systems Biology in Seattle, Washington. And Brian Palenik, a microbiologist at the Scripps Institution of Oceanography in La Jolla, California, cautions that many sequences that seem to belong to new protein families may in fact be members of known families that contain highly divergent

\section{Bush challenged on funding for children's study}

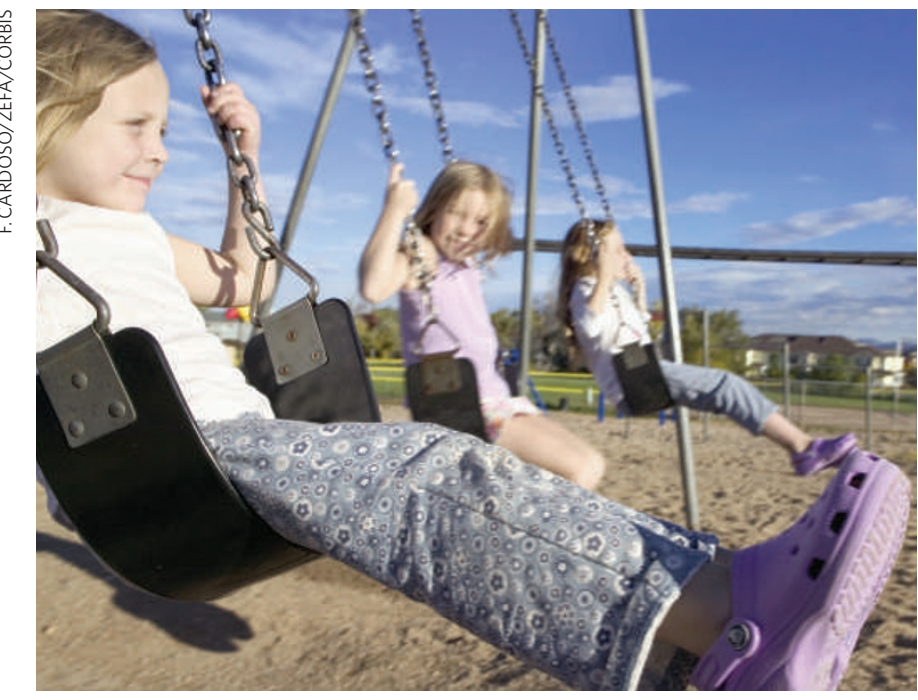

Swings and roundabouts: funding could yet be available to study kids' health.
A controversial US study of environmental effects on children's health got a boost last week, when the congressman who holds the House purse strings for the project vowed to keep it funded despite resistance from the White House.

At a hearing on Capitol Hill on 6 March, Representative David Obey (Democrat, Wisconsin) complained that President George W. Bush's budget request for 2008 eliminated funding for the National Children's Study, as the president had also done the previous year. Authorized by Congress in 2000 , the project would follow up 100,000 children from early in the womb until they reached their 21st birthday, examining the effects of everything from video games to chemical pollutants on their health and development. The study is planned for 105 sites nationwide and is expected to cost at least US $\$ 3.1$ billion over 25 years.

Although the study does not specifically target the benefits of apple pie, it might be expected to enjoy a similar popularity among politicians - who doesn't want to discover the environmental triggers of autism and asthma? But the cost is raising red flags.

"There's no opposition or scientific reluctance on our part" to doing the study, Elias Zerhouni, director of the US National Institutes of Health (NIH) in Bethesda, Maryland, told Obey at the hearing. 


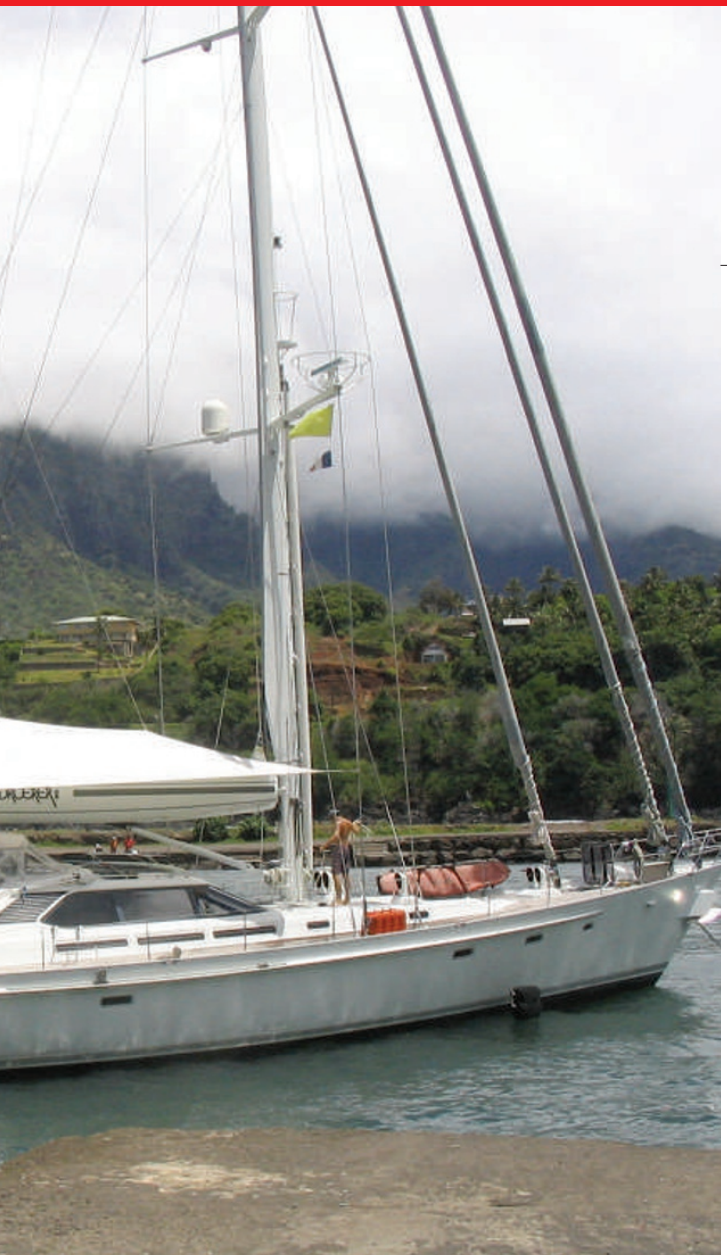

Sea of change: the Sorcerer II is obtaining DNA samples from oceans around the world.

sequences. Still, although the hard numbers might be toned down in the future, Orellana and Palenik don't question that the Global Ocean Sampling database contains a wealth of new proteins.
Already, researchers are tracing the course of protein evolution using the database. Others will search it for new enzymes that might have technological applications, or use it to learn more about microbial ecology. For instance, Jonathan Eisen, a study co-author and microbiologist at the University of California, Davis, will work to match gene fragments in the database with their host organism, a substantial technical challenge when dealing with unfamiliar microbes.

Such studies need to be followed by experiments to establish the function that the gene sequence actually has in the organism, warns Eugene Madsen, a microbiologist at Cornell University in Ithaca, New York. "You can overinterpret DNA sequence data," he says, "but if you're careful, you just use them as a clue and then they either lead to solving the mystery or they don't."

Dennis Hansell, a microbiologist at the University of Miami in Florida, adds that although his research won't entail direct analysis of the Global Ocean Sampling sequence data, the newfound wealth of microbial diversity has made him re-evaluate his picture of how microbes leave their chemical fingerprints in the ocean. He likens the collection of genomic sequences to characterizing all of the pigments an artist could use to paint a portrait. "It's blending the pigments and applying them that results in a Mona Lisa," Hansell says. "I'm looking at the Mona Lisa in my data, and this shows me what the pigments are."

Heidi Ledford

See Editorial, page 231.

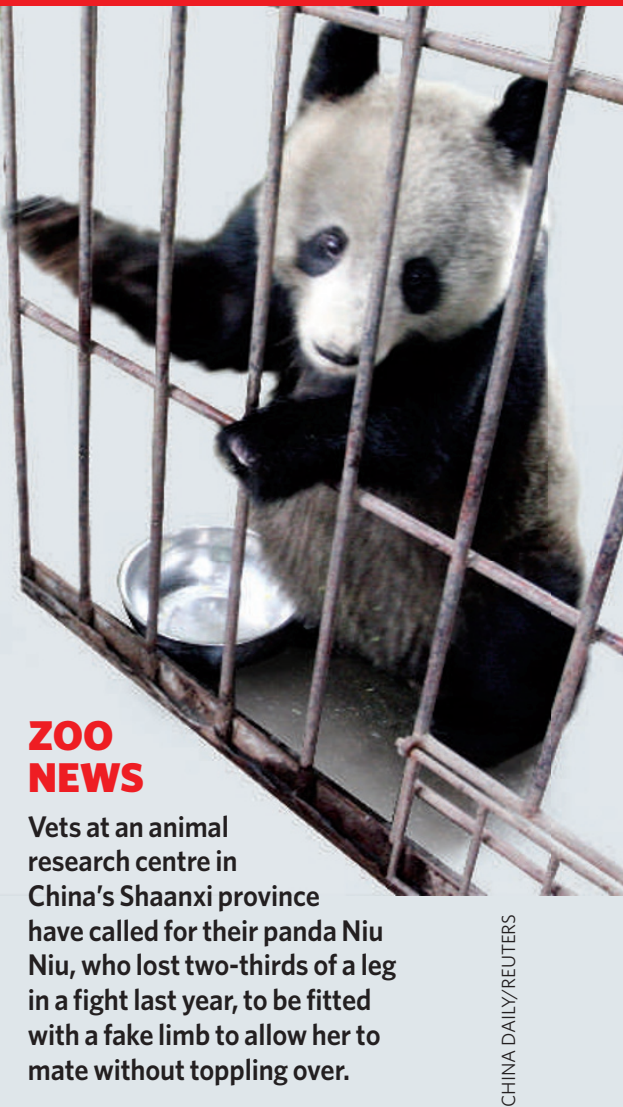

\section{OVERHYPED}

Is nothing safe from the perils of global warming? Apparently, the latest victim is the sex trade in Bulgaria, where brothel owners are claiming that their best girls have headed for the hills to entertain snowless skiers.

\section{SCORECARD}

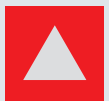

\section{Pluto}

New Mexico has declared that the

beleaguered rock should be re-declared as a planet....at least while in the skies over New Mexico. choices to maintain support for bench scientists and, in particular, young investigators. "Clearly, unless there were additional resources, it wouldn't have been wise to sacrifice the next generation [of scientists] for this study," he said.

Obey, who is chair of the House Committee on Appropriations, said that he would solve that problem in 2008 by restoring money for the children's study. "We are going to put that money back next year too," he says. "And it will not squeeze other research because we will expand the institutes' budget, just as we did this year." In February, Obey and his Senate counterparts added an extra $\$ 620$ million to the NIH's budget for 2007 (see Nature 445, 572-573; 2007), including $\$ 58$ million to fund the children's study. Early this

\section{"If there were a cheaper, smaller, faster way to answer the questions, you would do it. But there isn't.}

month, study administrators asked contractors to pitch proposals for managing up to 30 of the 105 sites. For 2008 , they are hoping for another $\$ 111$ million.

Duane Alexander, director of the National Institute of Child Health and Human
Development in Bethesda, Maryland, said that Obey's vow to deliver funding came as "a welcome surprise". The study sets out to answer big questions, Alexander says. "If there were a cheaper, smaller, faster way to answer them, you would do it. But there isn't. And as we get answers about environmental factors, it's going to pay for itself many, many, many times over."

Over 25 years the study is expected to grow up to join the ranks of massive population studies, such as the Framingham Heart Study, that have yielded troves of information on disease causes and associations. If, that is, it doesn't die in its infancy. Meredith Wadman

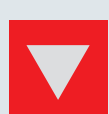

Space return flights Valentina Tereshkova, the first woman in space, has marked her 70th birthday by declaring herself ready to fly to Mars "without coming back".

\section{ROBOT NEWS}

South Korea is doing its bit to prevent future dystopia by drawing up a Robot Ethics Charter, one of the key points of which is that humans should maintain control over our electronic counterparts.

Sources: Reuters, Metro, FPSpace, BBC 